\title{
Cause and effect of climate variability and their various impacts
}

\author{
S.C. Dubey ${ }^{1}$, M.K. Shukla ${ }^{2}$, R.N. Ojha ${ }^{3}$, S.K. Tiwari ${ }^{4}$, R.K. Mishra ${ }^{5}$ and S.K.Pandey ${ }^{6}$ \\ 1, 2,3,4,5 Department of Physics, S.G.S. Govt. P.G. College, Sidhi (M.P.) Pin-486661, India. \\ ${ }^{6}$ Department of Physics, Rewa Engineering College, Rewa (M.P.) Pin-486002, India.
}

\begin{abstract}
This paper addresses the cause and effect of climate change and their various impacts. Earth's climate is determined by complex interactions among the Sun, oceans, atmosphere, cryosphere, land surface and biosphere. The Sun is the principal driving force for Earth's weather and climate. The Sun's energy is distributed unevenly on Earth's surface due to the tilt of Earth's axis of rotation. Over the course of a year, the angle of rotation results in equatorial areas receiving more solar energy than those near the poles. As a result, the tropical oceans and land masses absorb a great deal more heat than the other regions of Earth. The atmosphere and oceans act together to redistribute this heat. As the equatorial waters warm air near the ocean surface, it expands, rises and drifts towards the poles; cooler denser air from the subtropics and the poles moves toward the equator to take its place. This continual redistribution of heat is modified by the planet's west to east rotation and the Coriolis force associated with the planet's spherical shape, giving rise to the high jet streams and the prevailing westerly trade winds. The winds, in turn, along with Earth's rotation, drive large ocean currents such as the Gulf Stream in the North Atlantic, the Humboldt Current in the South Pacific, and the North and South Equatorial Currents. Ocean currents redistribute warmers waters away from the tropics towards the poles. The ocean and atmosphere exchange heat and water, carbon dioxide and other gases. By its mass and high heat capacity, the ocean moderates climate change from season to season and year to year. These complex, changing atmospheric and oceanic patterns help determine Earth's weather and climate.

Scientists all over the world are making predictions about the ill effects of Global warming and connecting events. The effect of global warming is increasing the average temperature of the Earth. A rise in Earth's temperatures can in turn root to other alterations in the ecology, including an increasing sea level and modifying the quantity and pattern of rainfall. These modifications may boost the occurrence and concentration of severe climate events, such as floods, famines, heat waves, tornados, and twisters. Other consequences may comprise of higher or lower agricultural outputs, glacier melting, lesser summer stream flows, genus extinctions and rise in the ranges of disease vectors. As an effect of global warming species like golden toad, harlequin frog of Costa Rica has already become extinct. There are number of species that have a threat of disappearing soon as an effect of global warming. As an effect of global warming various new diseases have emerged lately. These diseases are occurring frequently due to the increase in Earths average temperature since the bacteria can survive better in elevated temperatures and even multiply faster when the conditions are favorable. The global warming is extending the distribution of mosquitoes due to the increase in humidity levels and their frequent growth in warmer atmosphere. Various diseases due to ebola, hanta and machupo virus are expected due to warmer climates. The marine life is also very sensitive to the increase in temperatures. The effect of global warming will definitely be seen on some species in the water. A survey was made in which the marine life reacted significantly to the changes in water temperatures. It is expected that many species will die off or become extinct due to the increase in the temperatures of the water, whereas various other species, which prefer warmer waters, will increase tremendously. Perhaps the most disturbing changes are expected in the coral reefs that are expected to die off as an effect of global warming. The global warming is expected to cause irreversible changes in the ecosystem and the behavior of animals.
\end{abstract}

Key words: IPCC, TEC, climate change, global warming, 11 year solar cycle.

\section{Introduction}

Five layers of atmosphere surround Earth, from surface to outer space. Overall, the atmosphere reduces the amount of sunlight reaching Earth's surface by about 50\%. Greenhouse gases (including water vapour, carbon dioxide, nitrous oxide, methane, halocarbons, and ozone) compose about $2 \%$ of the atmosphere. In a clear, cloudless atmosphere they absorb about $17 \%$ of the sunlight passing through it. Clouds reflect about $30 \%$ of the sunlight falling on them and absorb about $15 \%$ of the sunlight passing through them. Earth's surface absorbs some sunlight and reradiates it as long-wave (infrared) radiation. Some of this infrared radiation is absorbed by atmospheric greenhouse gases and reradiated back to Earth, thereby warming the surface of Earth by more than would be achieved by incoming solar radiation alone. This atmospheric greenhouse effect is the warming process that raises the average temperature of Earth to its present $15^{\circ} \mathrm{C}$.

The Earth's magnetosphere and upper atmosphere can be greatly perturbed by variations in the solar luminosity caused by disturbances on the Sun. The state of near-Earth space environment is governed by the 
Sun and is very dynamic on all spatial and temporal scales [1]. The geomagnetic field which protects the Earth from solar wind and cosmic rays is also essential to the evolution of life; its variations can have either direct or indirect effect on human physiology and health state even if the magnitude of the disturbance is small. Geomagnetic storms are seen at the surface of the Earth as perturbations in the components of the geomagnetic field, caused by electric currents flowing in the magnetosphere and upper atmosphere. Ionospheric and thermospheric storms also result from the redistribution of particles and fields. Global thermospheric storm winds and composition changes are driven by energy injection at high latitudes. Storm effects may penetrate downwards to the lower thermosphere and may even perturb the mesosphere. Many of the ionospheric changes at mid-latitude can be understood as a response to thermospheric perturbations. The transient bursts of solar energetic particles, often associated with very large solar flares, have been observed to have effects on the Earth's middle and lower atmosphere, including the large-scale destruction of polar stratospheric and tropospheric ozone. A typical mid-latitude ionospheric storm has a relatively brief increase (positive phase) in F2 peak electron density (NmF2) and total electron content (TEC), followed by an extended decrease (negative phase), especially in the summer hemisphere. At low latitudes, the positive phase may be longer and the negative phase absent altogether. However, there are considerable variations in this scenario from storm-tostorm, depending on location, level of solar activity, magnitude of the geomagnetic disturbance, season, local time, time of day of the commencement, and the duration of the storm.

Of the many objects in the universe, only two are well known for our climate change and global warming, one is Earth itself and other the Sun. The Sun, which about five billion years old provides an unfailing source of light and energy [2]. The increase in greenhouse gases caused by human activity is often cited as one of the major causes of global warming. These greenhouse gases reabsorb heat reflected from the Earth's surface, thus trapping the heat in our atmosphere. This natural process is essential for life on Earth because it plays an important role in regulating the Earth's temperature. Today the use of fossil fuel for power and electricity is increased thousands times in compassion to pre-industrial revolution. Climate change holds the significant changes in physical and biological systems in all the continents and oceans. It also threatens to destabilize natural phenomena on a regional as well as global scale; some warning signs are already visible. Unprecedented occurrence of severe droughts, heat waves, storms, heavy precipitation, floods, cyclones, shifts in climate zones and seasonality, and increase in sea level and temperature have been reported from various regions of the globe. As these ill effects intensify, they will increasingly cause stress to our ecosystems and tribulations to the livelihood and resources of islands, beaches and coasts. The deterioration of the earth's ecosystems will jeopardize human health; precipitation patterns; water and food supplies; energy supplies; and the integrity of natural systems.

\section{Solar Variability \& Climate Change}

The Sun also poses a health and safety threat to humans [3] and all kinds of human activities [4]. Solar output varies both over the long-term (centuries), which will impact long-term climate trends, and over the shorter-term (the 11 year solar cycle). Observations of the Sun during the middle of the Little Ice Age (16501750) indicated that very little sunspot activity was occurring on the Sun's surface. The Little Ice Age was a time of a much cooler global climate and some scientists correlate this occurrence with a reduction in solar activity over a period of 88 or 176 years. Archibald [5] predicted that climate during the present solar cycle 24 and forthcoming solar cycle 25 would be significantly cold. The Sun is doing something interesting, and has been for the last few years. .As at late 2010, the progression of the current solar cycle 24 solar minimum indicates that a severe cool period is now inevitable, similar to that of the Dalton Minimum. According to research by NASA solar physicist David Hathaway solar cycle 25 peaking around 2022 could be one of the weakest in centuries. Therefore, it is time to put aside the global warming dogma, if we are moving into another little ice age the next little ice age would be much worse than the previous one and much more harmful than any warming may do.

The potential role of solar influences in modulating recent climate has been debated for many decades. The enhanced UV radiation released from the Sun during high solar activity increases the amount of ozone in the stratosphere. At times of minima in the 11-year sunspot cycle, less ozone is found. One consequence of these solar perturbations is to complicate the detection of human-induced depletion of the protective ozone layer; another may be to perturb the temperature at the Earth's surface, through connections that link the upper and lower parts of the atmosphere. Variations in temperatures, ozone amounts, and the altitude at which the atmosphere has a given pressure have been correlated with the solar cycle. Correlations of past solar activity with the historic climate record were reviewed by Brunetti [6] and detailed work on the 20th century temperature record in relation to solar cycle length was undertaken by Friis-Christensen and Lassen [7]. The Total Solar Irradiance (TSI) is integrated solar energy flux over the entire spectrum which arrives at the top of the atmosphere at the mean Sun-Earth distance. TSI has been monitored from 1978 by several satellites. The long-term solar irradiance variations might contribute to global warming over decades or hundreds of years. Sun has shown a slight cooling trend since 1960, over the same period that global temperatures have been warm. 
According to TSI variation trends in recent decades, the Sun has contributed a slight cooling influence but our globe is warmed up continuously. It is indication for a dangerous period and high awareness about global warming is most essential.

\section{Cosmic Radiation}

The Sun's magnetic field and the solar wind modulate the amount of high energy cosmic radiation that the earth receives. The galactic cosmic rays change the amount of $\mathrm{C}-14$ in the atmospheric $\mathrm{Co}_{2}$, which is best known as the isotope that archeologists use for dating biological archeological artifacts. The change in the C14 concentration in the atmosphere is dominated by variations in solar activity. When the solar activity is high the production of $\mathrm{C} 14$ is low, this is due to the shielding effect of the solar wind against cosmic rays. The C-14 content of, for example, annual rings of old trees may reveal something about the Sun's performance during the last few millennia. Some studies have indicated that there is a connection between long term climate change and Sun's activity [7, 8]. (One possible mechanism operating is that during high activity levels the decreased amount of galactic cosmic rays could lead to reduced cloud formation in the atmosphere, and hence to increased temperatures. The basis of the hypothesis of Svensmark and Friis-Christensen [9] is that weak solar activity causes a weak solar wind, which in turn increases the number of galactic cosmic rays penetrating the Earth's atmosphere. This increases low level cloud formation and the Earth's albedo.

\section{Greenhouse Gases And Global Temperature}

The world has warmed $0.74^{\circ} \mathrm{C}$ in the past hundred years due to increases in greenhouse gas concentrations. Global average temperature is forecast to rise $4^{\circ} \mathrm{C}\left(7.2^{\circ} \mathrm{F}\right)$ toward the end of the $21^{\text {st }}$ century. The real increase in carbon dioxide $\left(\mathrm{Co}_{2}\right)$ levels in our atmosphere began around the time of the Industrial Revolution (since 1750s). The main Greenhouse Gases $\sim \mathrm{Co}_{2}$, nitrous oxide and methane have all increased exponentially since the 1750s. The amount of $\mathrm{Co}_{2}$ that can be held in oceans is a function of temperature. $\mathrm{Co}_{2}$ is released from the oceans when global temperatures become warmer and diffuses into the ocean when temperatures are cooler. Initial changes in global temperature were triggered by changes in received solar radiation by the Earth through the Milankovitch cycles. The increase in $\mathrm{Co}_{2}$ then amplified the global warming by enhancing the greenhouse effect. The long term climate change represents a connection between the concentrations of $\mathrm{Co}_{2}$ in the atmosphere and means global temperature. Certain atmospheric gases, like carbon dioxide, water vapor and methane, are able to alter the energy balance of the Earth by being able to absorb long wave radiation emitted from the Earth's surface. Without the greenhouse effect, the average global temperature of the Earth would be a cold $-18^{\circ}$ Celsius rather than the present $15^{\circ}$ Celsius. $\mathrm{Co}_{2}$ concentrations in the atmosphere have increased from about $280 \mathrm{ppm}$ in pre-industrial times to $395 \mathrm{ppm}$ at present. These increases are projected to reach more than $560 \mathrm{ppm}$ before the end of the $21^{\text {st }}$ century.

\section{Climate Change And Sea Level Rising}

Climate change will exert unprecedented stress on the coastal and marine environment too. Climate change will increase the ocean temperature, cause sea level rise, and will have impact on ocean circulation patterns, ice cover, fresh water run-off, salinity, oxygen levels and water acidity. Sea level is rising around the world. In the last century, sea level rose 5 to 6 inches more than the global average along the Mid-Atlantic and Gulf Coasts, because coastal lands there are subsiding. Due to global warming, higher temperatures are expected to further raise sea level by expanding ocean water, melting mountain glaciers and small ice caps, and causing portions of Greenland and the Antarctic ice sheets to melt. The International Panel on Climate Change (IPCC) estimates that the global average sea level will rise between 0.6 and 2 feet in the next century [10]. As the sea rises, the outer boundary of these wetlands will erode, and new wetlands will form inland as previously dry areas are flooded by the higher water levels. The amount of newly created wetlands, however, could be much smaller than the lost area of wetlands - especially in developed areas protected with bulkheads, dikes, and other structures that keep new wetlands from forming inland. The IPCC suggests that if sea level rise could convert as much as 33 percent of the world's coastal wetlands to open water by 2080. Tidal wetlands are generally found between sea level and the highest tide over the monthly lunar cycle. As a result, areas with small tide ranges are the most vulnerable.

\section{Effects Of Climate Extremes On Human Health}

Weather is the complex and continuously changing condition of the atmosphere usually considered on a time-scale from minutes to weeks. The atmospheric variables that characterized weather include temperature, precipitation, humidity, pressure, and wind speed and direction. Climate is the average state of the atmosphere, and the associated characteristics of the underlying land or water, in a particular region over a particular timescale, usually considered over decades or longer time-scales. Climate variability is the variation around the average climate, including seasonal variations as well as large-scale variations in atmospheric and ocean circulation. Extreme climate events are expected to become more frequent as a result of climate change. Climate 
extremes can have devastating effects on human societies. History records widespread disasters, famines and disease outbreaks triggered by droughts and floods. These complex, large-scale disruptions exert their worst effects in poor countries but even the richest industrial societies are not immune. Climate can also affect infectious diseases that are spread via contaminated water or food. Water-related diseases are a particular problem in poor countries and communities, where water supplies and sanitation often are inadequate. Outbreaks of cholera, typhoid and diarrhoeal diseases can occur after flooding if the floodwaters become contaminated with human or animal waste, while drought reduces the water available for washing and sanitation and also tends to increase the risk of disease.

Forecasts of climate extremes can improve awareness and reduce adverse effects. Focusing attention on extreme events also may help countries to develop better means of dealing with the longer-term impacts of global climate change. Conversely, the pressures on the biosphere that drive climate change may cause critical thresholds to be breached, leading to shifts in natural systems that are unforeseen and rapid. Studying historical extremes of climate cannot forewarn on the consequences of such events. Rapid changes in climate during extreme events may be more stressful than slowly developing changes due to the greenhouse effect.

\section{References}

[1] V. Bothmer and I.A. Daglis, Space Weather: Physics and Effects, Springer Praxis Books, Environmental Sciences, 2006.

[2] L. Hartmann, J. Ballesteros-Paredes, E.A. Bergin, Ap.J., 562, 2001, 852

[3] S.J. Palmer, M.J. Rycroft, M. Cermack, Surv. Geophys., 27, 2006, 557.

[4] F. Jansen, R. Pirjola, R. Favre, Space Weather Hazard to the Earth? Swiss Re Publishing, Zurich, 2000.

[5] D. Archibald, Solar Cycles 24 and 25 and Predicted Climate Response Energy and Environment, 17, 2006, $29-38$.

[6] M. Brunetti, Memorie della Societa Astronomica Italiana, 74-3, 2003, 778-785.

[7] E. Friis-Christensen, K. Lassen, Science, 254, 1991, 698-700.

[8] K. Lassen, E. Friis-Christensen, J. Atmos. Terr. Phys., 57, 1995, 835-845.

[9] H. Svensmark, E. Friis-Christensen, Journal of Atmospheric and Solar-Terrestrial Physics, 59-11, $1997,1225-1232$.

[10] IPCC, 2007: Climate Change 2007: Impacts, Adaptation and Vulnerability Contribution of Working Group II to the Fourth Assessment Report of the Intergovernmental Panel on Climate Change [Parry, Martin L., Canziani, Osvaldo F., Palutikof, Jean P., van der Linden, Paul J., and Hanson, Clair E. (eds.)]. Cambridge University Press, Cambridge, United Kingdom, 1000 pp. 